\title{
Investigating Methane Adsorption Potential of Malaysian Coal for Coal Bed Methane (CBM) Study
}

\author{
Saleem Qadir Tunio \\ Universiti Teknologi Petronas (UTP) Malaysia \\ Swapan Kumar Bhattacharya \\ Universiti Teknologi Petronas (UTP) Malaysia \\ Khalil Rehman Memon \\ Mehran University of Engineering \& Technology Pakistan \\ Sonny Irawan
}

Universiti Teknologi Petronas (UTP) Malaysia

Aung Kyaw

UCSI Malaysia

Mohd. Faisal Abdullah

Sarawak Coal Resources Malaysia

Email: saleem_tunio@petronas.com.my

Doi:10.5901/mjss.2014.v5n27p178

\section{Abstract}

\begin{abstract}
Methane in coal can be present as free gas or as an adsorbed layer in the internal surfaces of the coal micropores. Methane gas is adsorbed to the internal surface area of the coal associated with high pressure and exists as a monomolecular layer on the internal surface of the coal matrix. The only way to produce these gasses is by reducing the pressure within the coal matrix until the gas can be desorbed. A comparative study is made on the adsorption potential of methane gas in Malaysian coal with other producing CBM basins. The Langmuir isotherm shows that the amount of methane adsorbed in Sarawak coal is 14.11 scf/tonne at 36 psia where as in Piceance basin it amounts to 30 scf/tonne at 36 psia and in Powder River Basin is 6.52 scf/tonne at 36 psia. This suggests Sarawak coals of Malaysia also possess comparable methane adsorption potential to other producing CBM fields. Results also suggest that the adsorption amount depends on depth only for particular coal but the amount does not depend on the depth of varieties of coal. Therefore Malaysian coal will be successful CBM producer only if it has got the source of methane at greater depth.
\end{abstract}

Keywords: Methane; Adsorption potential; Coal Bed Methane (CBM).

\section{Introduction}

The amount of methane in coalbed can be verified by adsorption isotherms and also by gas measurements using cores /cuttings of coal sample. Methane in the coalbed can be present as free gas within the pores or as an adsorbed layer in the internal surfaces of the coal micropores.

Methane gas is adsorbed to the internal surface area of the coal due to the high pressure. Coalbed methane exists as a monomolecular layer on the internal surface of the coal matrix [J. R. Fanchi, 2005]. The only way to produce these gasses is by reducing the pressure within the coal matrix until the gas can be desorbed.

Coal has a lot of micropores and macropores along with natural fractures or cleats where the methane gas can be stored. Most of the gas is stored by adsorption in the coal matrix. Hence, production is based on pressure depletion [K. 
Aminian]. The amount of gas stored in coals can be estimated using Langmuir's equation:

$\mathrm{G}_{\mathrm{S}}=\left(\mathrm{V}_{\mathrm{L}} \mathrm{P}\right) /\left(\mathrm{P}_{\mathrm{L}}+\mathrm{P}\right)$

Where:

$\mathrm{G}_{\mathrm{s}}=$ Gas storage capacity (SCF/tonne),

$P=$ Pressure (psia),

$V_{L}=$ Langmuir volume constant (SCF/tonne),

$\mathrm{PL}_{\mathrm{L}}=$ Langmuir pressure constant (psia),

Meng. et. al, 1996 suggested that primary and secondary cleats are also means for gas storage within the coal.

CBM trapping is identified with sorption isotherms that indicates the maximum volume of methane that a coal can store in an equilibrium conditions at a given pressure and temperature. Typically these types of isotherms shows initial reservoir gas content with respect to the pressure, critical desorption pressure and abandonment conditions.

Gas cannot flow until reservoir pressure is lesser than critical pressure as shown in figure 1 . The recovery factor and recoverable reserves can be determined by comparing the initial and abandonment gas content values on the isotherm curve.

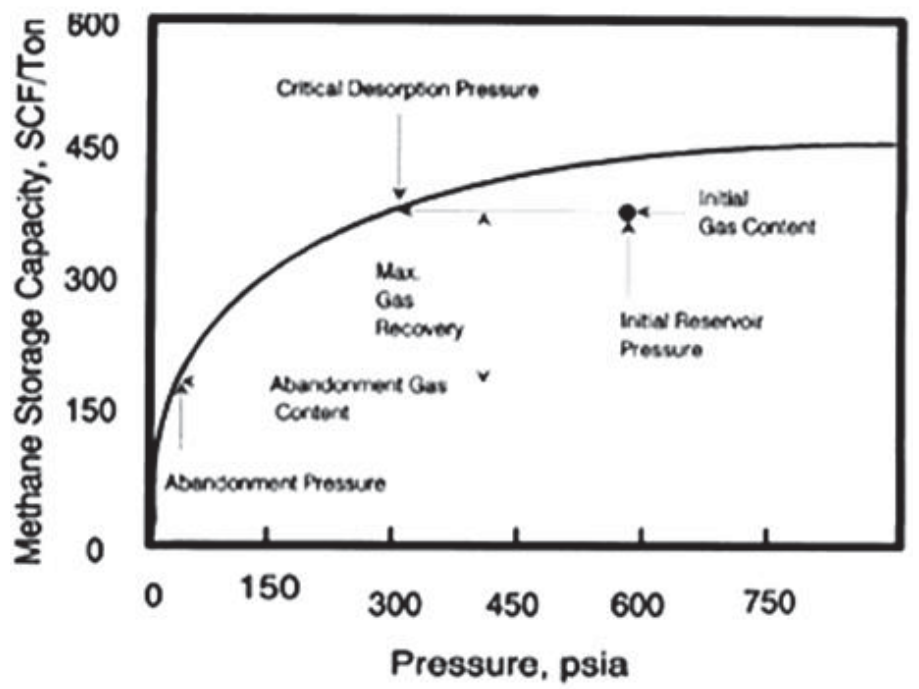

Figure 1. Methane storage capacity vs. pressure. [E. R. (Ross) Crain, 2011]

Sorption is defined as the physico-chemical nature of the methane storage in the coal and in general, following are the states in which methane is stored in coal. ((Ceglarsk-Stefańska and Brzóska, 1998; Ceglarsk-Stefańska and Zarębska, 2002; Rice, 1993)

\subsection{Free state}

It is that state, where methane molecules are within the fractures and the macropores.

\subsection{Adsorbed state}

That state in which the methane molecules have a physical adsorption within micropore complexes.

\subsection{Absorbed state}

In this state, methane is dissolved within the molecular structure of the coal.

A coalbed methane gas in the reservoir is stored in two locations: [Fekete Associates Inc, 2011]

1. Adsorption in the coal matrix.

2. Compression fracture system of coal. This is often the "free gas" as referred to, and generally living in a small volume. 
As the sorption mechanism deals with the methane storage in coal, diffusion theory will be helpful to know the movement of methane from one place to another (i.e. from one pore to the other until the methane molecule approaches the cleats). Moore, 2012 in his studies suggests that Fick's law can be used to determine the gas diffusion [T. A. Moore, 2012]. Initially the Fick's law was hard to confirm but with the time, it was supported through the experimental stuff [J. Philibert, 2005]. The Fick's law is stated as;

$$
F=D \times(d C / d x)
$$

Where,

$\mathrm{F}=$ Diffusion flux,

$\mathrm{D}=$ Diffusion coefficient,

$(\mathrm{dC} / \mathrm{dx})=$ concentration gradient

The Langmuir equation is used to determine the maximum gas storage capacity of a reservoir and the equilibrium pressure.

Methane is trapped in coal beds by adsorption on the free surface. The free surface is mainly available in the micropores and partly in different cleats. The average percentage of micropores $\left(1.2 \times 10^{-7} \mathrm{~cm}\right.$ diameter) in a coal increases with rank and ranges from $19.3 \%$ in lignites to $75 \%$ in anthracites. The effective molecular diameter of adsorbed methane is $4.1 \times 10^{-8} \mathrm{~cm}$ suggesting a maximum of three molecules can be accommodated in a micropore.

The commitment of optimized production of methane depends on the amount adsorbed on the coal surface. Methane in the micropore can be accommodated either by solution in pore water or adsorption or as free gas under pressure. If it is dissolved in water then for CBM production it is not useful because the dissolved gas will be expelled during dewatering phase of the well completion. It is only the free gas and the adsorbed gas that need to be evaluated for optimized production.

Langmuir assumed a mono-layer of adsorption in selective locales on the adsorbent whereas many of the present day models assumed multilayers of adsorbates (i.e. BET). Problem arises with the concept of layering during adsorption process whereby it is difficult to think of adsorption of methane over a methane layer. With higher pressure methane can be accommodated as free gas but will not be adsorbed on any methane surface. It is therefore necessary to understand how methane molecule is trapped in the micropores of coal bed.

Methane is trapped in pores of the coal either as a free gas or as an adsorbate (monolayer or multilayers as shown in figure 2) as a function of pressure and temperature "adsorption process". [Connexions, 2012; M. K. Kazi, 2009]

Coal has a dual pore system consisting of micropores and macropores. When the molecular structure of coal change with temperature and time, a point is reached where thermogenic methane is evolved in large volumes, micropores engages extraordinary amount of methane per unit of coal and cleats permeate the coal to move the surplus methane. Thus, methane is generated to be stored and dissolute over geologic time. [Rogers et. al. 2007]

The mechanical properties and permeability of the coal is determined at large extent by the network of the natural fractures and cleats in the coal. Therefore, completing a well and producing methane from a coal bed, it is essential to understand the origin and role of the variety of natural fractures.

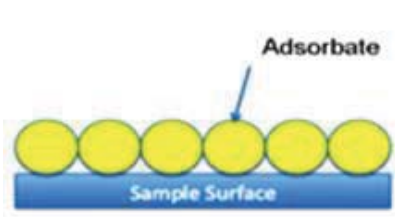

(a)

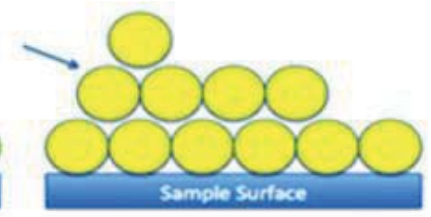

(b)

Figure 2. Adsorbate behaviors "Monolayer and Multilayers" [Connexions, 2012; M. K Kazi, 2009]

Gases or liquids molecules or the solutes in solutions get adhered to the solid surface [Amirta laboratories, 2012]. In adsorption process two substances are involved namely as adsorbent and adsorbate [Amirta laboratories, 2012; Chemistry Department, University of Florida 2012].

Absorbent is that solid or the liquid on which adsorption occurs whereas the adsorbate is that gas or liquid or the solute from a solution which gets adsorbed on the surface. In adsorption process, molecules of one substance are present in higher concentration at the surface of another substance. [Amirta laboratories, 2012]

Increasing the temperature will decrease the volume of the adsorbate (methane) but it will go reverse in case of high pressure (i.e. the volume of methane increase as suggested by Langmuir). [Rogers et. al, 2007] 
Moore, 2012 modified from Bustin and Clarkson, 1998 the relationship between the total percent of vitrinite (raw coal in figure 3) and the maximum gas holding capacity which shows that the higher the percentage of total vitrinite will results in higher methane adsorption (m³/t, DAF). [R. M Bustin, 1998; T. A. Moore, 2012]

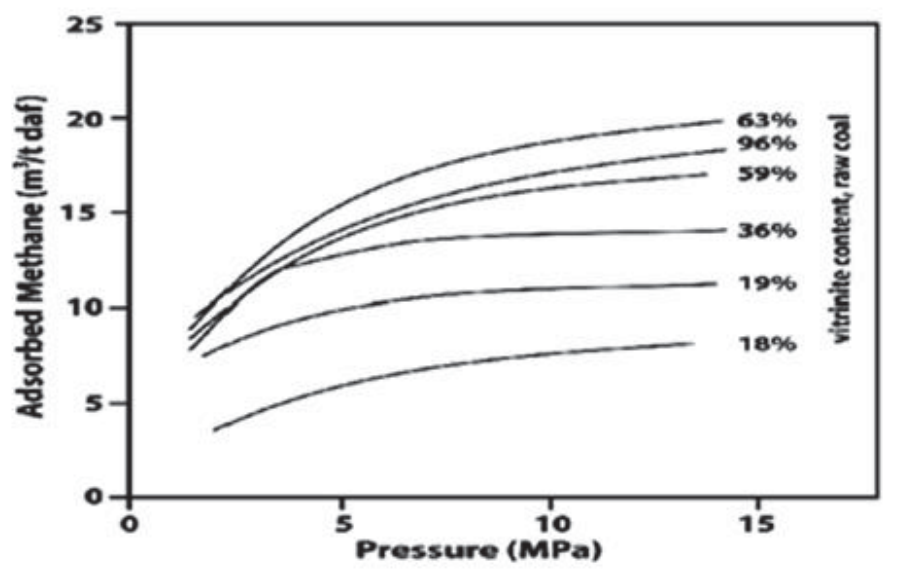

Figure 3. Relationship of vitrinite percentages with adsorbed methane and the pressure. [T. A. Moore, 2012]

The scope and objective of this study covers the methane adsorption potential of Malaysian coal and comparison of the measured adsorption potential with methane adsorption of selected CBM producers. This study will therefore lead to further possibilities of CBM potential in Malaysia.

\section{Research Methodology}

The study is performed using methane adsorption isotherms analysis to get the familiarity with the gas storage in coal samples either in cleats and/or the micro-pores. These micro-pores are responsible to trap methane molecule which is directly related to the diameter of that micro-pore. Adsorption isotherms are compared for the gas content measurements of different coal seams.

\section{Findings and Discussion}

Figure.4 shows the methane adsorption isotherm of Malaysian coal in two different values (i.e. as received and DAF "dry ash free" basis).

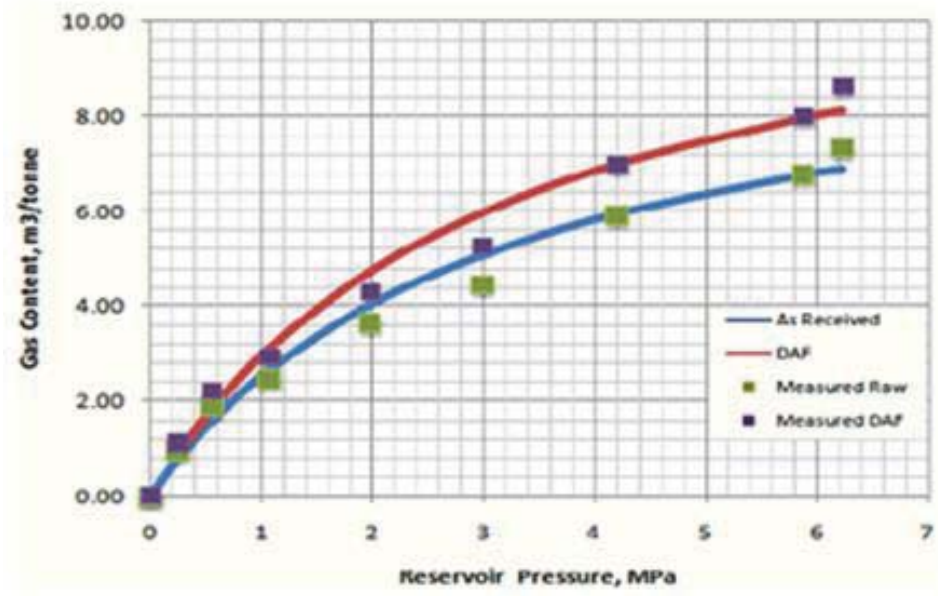

Figure 4. Adsorption isotherm of Malaysian coal sample. 
From the figure 4, it is noticed that the sample when it is DAF (dry ash free) adsorbed more gas at high pressure (i.e. at $6.23 \mathrm{MPa}$ or $61.483 \mathrm{~atm}$ will result $8.64 \mathrm{~m}^{3} /$ tonne) as compared to the sample which is measured in the condition as it is received will result $7.32 \mathrm{~m} /$ tonne. If the lowest pressure $(0.25 \mathrm{MPa}$ or $2.467 \mathrm{~atm})$ is taken into consideration then it shows that the methane volume adsorbed in DAF is $1.11 \mathrm{~m}^{3} /$ tonne whereas the sample results the volume as 0.94 $\mathrm{m}^{3} /$ tonne in the condition as it is received.

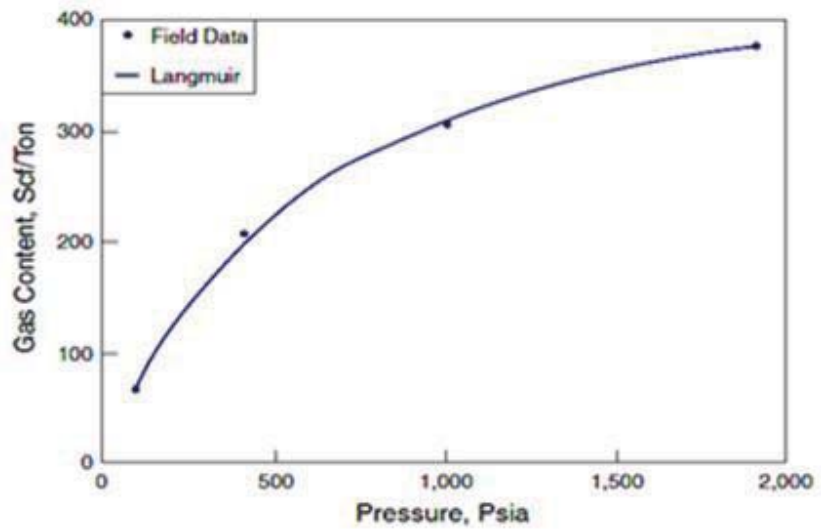

Figure 5. Cameo coal (Piceance basin) adsorption isotherm. [Rogers et. al, 2007]

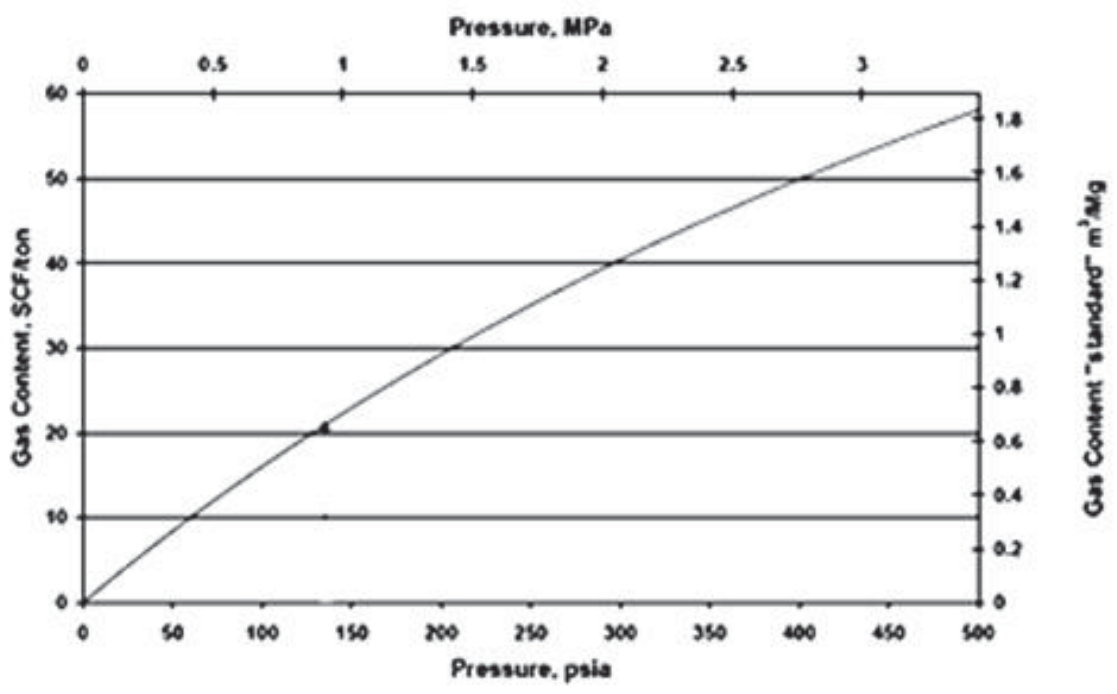

Figure 6. Modified representation of United States Bureau of Land Management (US BLM) adsorption isotherm for Powder River Basin, Wyoming. [F.M. Carlson, 2006]

The methane adsorption of Malaysian coal was then compared with couple of CBM producing fields/basins in the world like (Piceance Basin and Powder River Basin in figure $5 \& 6$ ). The Langmuir isotherm shows that the minimum amount of methane adsorbed in Malaysian coal is $\left(0.4 \mathrm{~m}^{3} /\right.$ tonne or $14.11 \mathrm{scf} /$ tonne at $\left.36 \mathrm{psia}\right)$ where as in Piceance basin shows almost $\left(0.85 \mathrm{~m}^{3} /\right.$ tonne or $30 \mathrm{scf} /$ tonne at $\left.36 \mathrm{psia}\right)$ and Powder River Basin shows $\left(0.185 \mathrm{~m}^{3} /\right.$ tonne or $6.52 \mathrm{scf} /$ tonne at 36 psia). This suggests that Malaysian coal also have good methane adsorption potential compared to other producing CBM fields.

Results also suggest that the adsorption amount depends on depth only for particular coal but the amount does not depend on the depth of varieties of coal. This has been confirmed when these basins were compared with respect to their depths (i.e. Piceance Basin as 12,200 ft and Powder River Basin as 2,500 ft). 


\section{Concluding Remarks}

It is concluded that the Malaysian coal do have high potential for methane adsorption. Therefore Malaysian coal will be successful CBM producer at greater depth only if it has got a definite source of methane.

\section{Acknowledgement}

The author(s) would like to pay THANKS to; Universiti Teknologi PETRONAS (UTP) for supporting this research work, Jabatan Minerals and Geoscience (JMG) Malaysia and Sarawak Coal Resources (SCR) Malaysia for their permissions and support to visit their coal mines for this research study.

\section{References}

Amirta laboratories, India, (Source: http://amrita.vlab.co.in/?sub=2\&brch=190\&sim=606\&cnt=1) as on 1st Feb 2012.

Chemistry Department, University of Florida, Gas Adsorption, (Source: http: //www.chem.ufl.edu / itt/4411L_f00/ads/ads_1. html) as on 5th Feb 2012.

Connexions, BET Surface Area Analysis of Nanoparticles, (Source:http://cnx.org/content /m38278/latest/?collection=col10699/latest as on 3rd Feb 2012.

D. D. Rice. (1993). Composition and origins of coalbed gas, In: Law, B.E., Rice, D.D. (Eds.), Hydrocarbons from Coal, 1993: AAPG Studies in Geology, 38. American Association of Petroleum Geologists, Tulsa, Oklahoma, pp. 159-184.

E. R. (Ross) Crain. (2011). Welcome to Crain's Petrophysical handbook, (Source: http://www.spec2000.net/17-speccbm.htm) as on 02 $2^{\text {nd }}$ Oct' 2011.

Fekete Associates Inc, Theory and Equations, Coal Bed Methane Production, (Source:http://www.fekete.com/software/cbm/medial webhelp/c-te- production.htm) as on $15^{\text {th }}$ Oct' 2011.

F.M. Carlson, SPE, Yates Petroleum Corp. (2006). Technical and Economic Evaluation of Undersaturated Coalbed Methane Reservoirs, paper no. SPE 100224 presented for presentation at the SPE Europec/EAGE Annual Conference and Exhibition held in Vienna, Austria, 12-15 June 2006.

G. Ceglarsk-Stefańska, K. Brzóska. (1998). The effect of coal metamorphism on methane desorption, 1998, Fuel 77, Pp. 645-648.

G. Ceglarsk-Stefańska, K. Zarębska. (2002). The competitive sorption of $\mathrm{CO} 2$ and $\mathrm{CH} 4$ with regard to the release of methane from coal, Fuel Processing Technology 2002, 77-78, Pp. 423-429.

J. Philibert. (2005). One and a half century of diffusion, 2005, Fick, Einstein, before and beyond. Diffusion Fundamentals 2, 1-10.

J. R. Fanchi. (2005). Principles of Applied Reservoir Simulation, (3rd Edition), 2005, Gulf Professional Publishing. (E-book on Elsevier)

K. Aminian, Evaluation of Coalbed Methane Reservoirs, Petroleum \& Natural Gas Engineering Department, West Virginia University, USA. (Source: http://karl.nrcce.wvu.edu/regional/CoalbedMethane_Aminian_Paper_2.pdf) as on 5th Jan 2012.

K. Aminian, Coalbed Methane - Fundamental Concepts, Petroleum \& Natural Gas Engineering Department, West Virginia University, USA. (Source: http://karl.nrcce.wvu.edu/regional/coalbedmethane_aminian_paper_1.pdf) as on 5th Jan 2012.

M. K Kazi. (2009). Ph.D. Student, Nanyang Technological University: Adsorption Isotherms, 1 st April 2009.

R. M Bustin, C.R. Clarkson. (1998). Geological controls on coalbed methane reservoir capacity and gas content, International Journal of Coal Geology, 1998, Volume 38, Pp. 3-26.

R. Rogers, M. Ramurthy, G. Rodvelt, Mike Mullen. (2007). Coal Bed Methane- Principles and Practices, 3rd Edition 2007, Oktibbeha Publishing Co., LLC, Starkville, MS.

T. A. Moore. (2012). Coalbed Methane-A Review, International Journal of Coal Geology 2012, Volume 101, Pp. 36-81

Y. F. Meng, P.Y. Luo \& L. Jin. (1996). Why low permeability and how does it affect coalbed methane supply in coal seams in China, paper no. 37382- MS presented in SPE Eastern Regional Meeting, 23-25 October 1996, Columbus. Ohio. 